\title{
INTEGRASI SMART ATTENDANCE BAGI DOSEN SEBAGAI UPAYA PENINGKATAN KINERJA
}

\author{
Irman Effendy ${ }^{1}$, Ahmad Mutatkin Bakti*2 \\ ${ }^{1}$ Program Studi Sistem Informasi, Universitas Bina Darma \\ 2Program Studi Teknik Informatika, Universitas Bina Darma \\ Jl. Ahmad Yani No 3 Seberang Ulu I Palembang, 0711515582 \\ Email: 1irman_effendy@binadarma.ac.id, 2mutatkin@binadarma.ac.id
}

\begin{abstract}
Attendance is a routine that is usually for someone who works well as an employee in the formal sector. Attendance is also an assessment of performance in tertiary institutions such as that conducted at Bina Darma University. Bina Darma University in evaluating the performance of lecturers' assessment components consisting of tri dharma and non tri dharma scores. Tri Dharma assessment includes teaching, research, service, and support. While non-tri dharma includes attendance (daily and briefing), rank, English language skills, Indonesian language skills, and the use of elearning. the problem that often arises when evaluating performance is in the field of discipline (presence). Some of the problems are: (1) lecturers often forget to make a presence in time and return, (2) the number of requests for repairs presence, (3) Summary of monthly presence disturbed. Based on these problems in this research conduct the development of smart attendance using the waterfall method. The waterfall method has five stages: communication, planning, medeling, construction and deployment. The results of the development is a smart attendance that can display information in an integrated manner starting from the presence machine, academic information systems and reporting.
\end{abstract}

Keywords: Attendance, Lecturers' Performance, Smart Attendance

\section{Abstrak}

Kehadiran merupakan sebuah rutinitas yang biasanya dilakukan bagi seseorang yang bekerja baik sebagai karyawan ataupu pegawai dalam sektor formal. Kehadiran juga menjadi penilaian kinerja di perguruan tinggi seperti yang dilakukan pada Universitas Bina Darma. Universitas Bina Darma dalam melakukan penilaian kinerja dosen komponen penilaian yang terdiri dari nilai tri dharma dan non tri dharma. Penilaian tri dharma meliputi pengajaran, penelitian, pengabdian, dan penunjang. Sedangkan non tri dharma meliputi kehadiran (harian dan brifing), kepangkatan, kemampuan bahasa inggris, kemampuan Bahasa Indonesia, dan penggunaan elearning. permsalahan yang sering muncul ketika melakukan penilaian kinerja yaitu pada bidang kedisiplinan (presensi). Beberapa masalah yaitu: (1) dosen sering kali lupa melakukan presensi waktu masuk dan pulang, (2) banyaknya permohonan perbaikan presensi, (3) perekapan presensi bulanan yang terganggu. Berdasarkan permasalahan tersebut didalam penelitian ini dilakukan pengembangan integrasi presensi dalam bentuk smart attendance menggunakan metode waterfall. Metode waterfall memiliki lima tahapan yaitu communication, planning, medeling, construction dan deployment. Hasil pengmbangan yang dilakukan berupa smart attendance yang dapat menampilkan informasi secara intergrasi mulai dari mesin presensi, sistem informasi akademik dan pelaporan.

Kata kunci: Kehadiran, Kinerja Dosen, Smart Attendance

Integrasi Smart Attendance Bagi Dosen Sebagai Upaya Peningkatan Kinerja (Irman Effendy)| 317 


\section{PENDAHULUAN}

Presensi atau kehadiran merupakan sebuah rutinitas yang harus dilakukan bagi seseorang dalam bekerja baik sebagai karyawan ataupu pegawai. Untuk melihat kinerja seorang karyawan atau pegawai maka dilakukan pencatatan kehadiran. Dengan adanya catatan maka dapat dilihat bagaimana seorang karyawan atau pegawai disiplin dalam bidang kehadiran untuk bekerja [1]. Kondisi tersebut juga terjadi jika bagi seorang dosen, karena dosen dalam kesehariannya harus melakukan tri dharma perguruan tinggai yang meliputi pendidikan, penelitian, dan pengabdian. Selain itu juga dosen saat ini sebagian besar telah mendapatkan tunjangan sertifikasi dosen dimana akan selalu dilakukan pemantauan oleh pemerintah dalam bidang kehadiran dengan cara inspeksi berkas ke perguruan tinggi sampel. Sehingga dapat dikatakan bahwa kehadiran merupakan komponen penting yang harus ada dalam kegiatan bekerja.

Kehadiran juga menjadi komponen penting dalam penilaian kinerja. Karena pengukuran kinerja dapat dilakukan dengan melihat kehadiran seseorang. Kondisi tersebut terjadi hamper disemua penilaian kinerja karyawan ataupun dosen. Di Universitas Bina Darma dalam melakukan penilaian kinerja dosen untuk diberikan insentif tahunan dilakukan perhitungan dengan komponen penilaian yang terdiri dari nilai tri dharma dan non tri dharma. Untuk penilaian tri dharma meliputi pengajaran, penelitian, pengabdian, dan penunjang. Sedangkan non tri dharma meliputi kehadiran (harian dan brifing), kepangkatan, kemampuan bahasa inggris, kemampuan Bahasa Indonesia, dan penggunaan elearning [2]. sebagai bukti kinerja pengajaran berupa surat keputusan mengajaran, membimbing dan hal yang terkait dengan akademik, sedangkan penelitian berupa artikel pada jurnal, buku maupun karya ilmiah laiinya. Untuk pengabdian dibuktikan dengan laporan pengabdian dan penunjang dibuktikan dengan surat tugas atau sejenisnya . Kondisi yang berbeda untuk penilaian non tri dharma, pada kehadiran harian dilihat jumlah menit keterlambatan datang dan kecepatan pulang sedangkan brifing dilihat jumlah kehadiran brifing. Kepangkatan dilihat dari jenjang akademik dan impasing, kemampuan basaha inggris dan Bahasa Indonesia dibuktikan dengan sertifikat kemampuan berbahasa dan penggunaan elearning dilihat dari jumlah hit pengguna.

Dari semua komponen penilaian yang sering kali mengalami kendala yaitu dalam bidang presensi atau kehadiran. Pemasalahan yang muncul bukan ketika melakukan penlianan melainkan pada proses presensi seharai-hari. Permasalahan atau kendala yang sering kali muncul yaitu: (1) dosen sering kali lupa apakah mereka telah melakukan presensi waktu masuk dan pulang, (2) banyaknya permohonan perbaikan presensi oleh dosen yang disebabkan lupa, (3) perekapan presensi bulanan yang terganggu. Untuk itu agar kondisi tersebut dapat diminimalisir dapat digunakan semua sistem informasi presensi yang terintegrasi baik presensi pelaporan maupun notifikasi bagi dosen berupa Smart Attendance dengan fungsi utama sebagai remainder yang terintegrasi secara menyeluruh.

Penelitian berkaitan dengan presensi sendiri telah banyak dilakukan, karena presensi sendiri merupakan salah satu komponen penting dalam dunia kerja. Penelitian tersebut seperti yang dilakukan pada sebuah perusahaan yang

Integrasi Smart Attendance Bagi Dosen Sebagai Upaya Peningkatan Kinerja (Irman Effendy)|318 
menekankan manajemen cuti dan presensi karyawan [3]. Sedangkan peneltian lain berkaitan dengan presensi penunjang tenaga pendidik atau karyawan [4]. Dari kedua kajian tersbut menunjukkan bahwa presensi yang dihasilkan hanya sebatas bagaimana seseorang dapat melakukan presensi dan pelaporan saja. Subtansib dari presensi yang dilakukan dengan objek utama karyawan atau tenga penunjang pendidik. Sehingga pada penelitian ini akan dilakukan kajian yang berbeda baik dari porses bisnis yang akan diselesaikan maupun teknik presensi dan metode pelaporan presensi.

Untuk itu didalam penelitian ini akan dilakukan pengembangan dan implementasi smart attendance yang terintegrasi sebagai upaya peningkatan kinerja dosen dalam bidang kedisiplinan. Untuk mendapatkan smart attendance yang sesuai harapan maka dalam proses pengembangan metode yang digunakan yaitu metode waterfall. Metode ini memiliki proses pengembangan sebanyak lima tahapan yaitu communication, planning, modeling, construction, dan deployment. Dengan demikian proses pengembangan dapat dilakukan secara terstruktur.

\section{METODOLOGI PENELITIAN}

Untuk mencapai sebagaimana tujuan yang telah dikemukakan maka sebagai langkah-langkah penyelesaian dan proses pengerjaan penelitian digunakan dua metode yaitu metode penelitian yang digunakan untuk menyajikan atau menjelaskan hasil peneltian dan metode pengembangan yang digunakan untuk melakukan proses pengerjaan Smart Attendance. Masing-masing metode tersebut dapat dijelaskan sebagai berikut.

\subsection{Metode Penelitian}

Penyajian hasil penelitian digunakan sebuah metode deskriptif. Tujuan penggunaan metode deskriptif karena metode ini mampu untuk menjelaskan fakta atau kondisi dari sebuah kajian. Selain itu juga metode ini menekankan atau berfokus pada pandangan peneliti terhadap objek yang diteliti [5]. Untuk itu metode deskriptif sangat tepat digunakan dalam menjelaskan bagaimana implementasi dari hasil penelitian Smart Attendance sebagai upaya peningkatan kinerja dosen.

\subsection{Metode Pengembangan}

Untuk mencapai tujuan bagaimana melakukan implementasi Smart Attendance sebagai upaya peningkatan kinerja dosen maka proses pengerjaan atau pembuatan Smart Attendance tersebut digunakan metode waterfall. Metode ini memiliki lima tahapan utama seperti yang diperlihatkan pada Gambar 1. Pengerjaan yang dilakukan seperti pada Gambar 1 yaitu komunikasi, perencanaan, pemodelan, kontruksi, dan penggambungan [6]. 


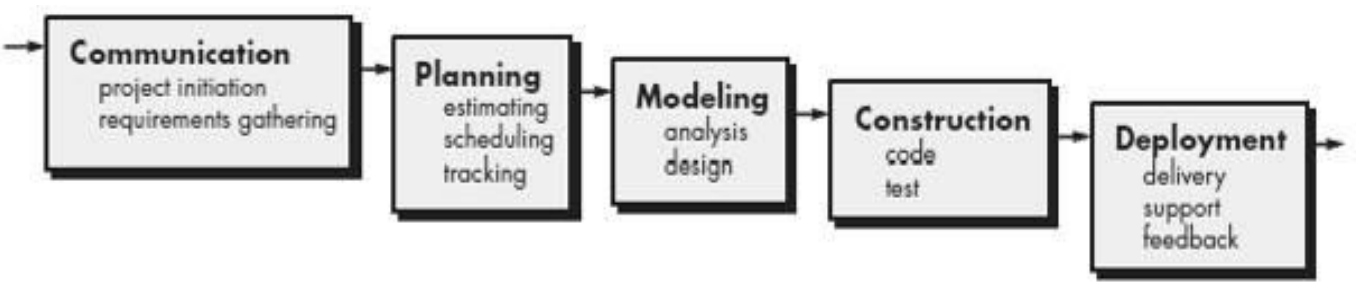

Gambar 1. Metode Waterfall [7]

a. Communication, fase komunikasi terdiri dari dua tahapan yaitu inisiasi projek dan pengumpulan kebutuhan. Pada fase inisiasi dilakukan pertemuan sebagai langkah awal pekerjaan untun membangun Smart Attendance bagi dosen ke pihak Universitas. Sedangkan pengumpulan kebutuhan dilakukan pengumpulan kebutuhan untuk mencapai Smart Attendance bagi dosen agar meningkatnya kinerja terutama dalam bidang kesiplinan atau kehadiran.

b. Planning, fase perencanaan terdiri dari tiga tahapan yaitu estimasi, penjadwalan, dan pelacakan. Pada tahapan estimasi dilakukan perhitungan biaya yang diperlukan dalam proses pengembangan dan implementasi Smart Attendance, sedangkan fase penjadwalan dilakukan pembuatan jadwal kegiatan pengembangan sampai dengan implementasi. Terakhir fase pelacakan merupakan pembuatan rencana review atau cek kualitas terhadap hasil pekerjaan dari tiap-tiap tahapan.

c. Modeling, fase pemodelan terditi dari dua fase yaitu analisis dan perencangan. Kedua fase tersebut saling terkait dimana fase analisis dilakukan analisis terhadap kebutuhan dan dituangkan dalam bentuk perancangan baik itu perancangan proses maupun antarmuka.

b. Construction, fase kontruksi memiliki dua tahapan yaitu pengkodean dan pengujian. Kedua tahapan tersebut dikerjakan beringan. Proses pekerjaan dalam melakukan pengembangan Smart Attendance dilakukan pengkodean lalu hasil pengkodean langsung dilakukan uji coba atau pengujian.

c. Deployment, fase ini merupakan fase terakhir yaitu pemberian Smart Attendance yang telah dikerjakan serta melihat umpan balik oleh pengguna. Jika terdapat masukan dilakukan perbaikan yang diperlukan.

\section{HASIL DAN PEMBAHASAN}

Dari hasil proses pengembangan menggunakan metode waterfall seperti yang diperlihatkan pada Gambar 1 maka dapat dijelaskan proses masing-masing tahapan sebagai berikut.

\subsection{Comunication}

Fase komunikasi terdiri dari dua tahapan yaitu inisiasi projek dan pengumpulan kebutuhan. Pada fase inisiasi dilakukan pertemuan sebagai langkah awal pekerjaan untun membangun Smart Attendance bagi dosen ke pihak Universitas. Pertemuan yang dilakukan melibatkan berbagai pihak yang berkepentingan yang terdiri dari Direktorat Sumber Daya Manusia, Direktorat Penjamin Muti, Direktorat Sistem dan Teknologi Informasi. Sedangkan pengumpulan kebutuhan dilakukan pengumpulan kebutuhan untuk mencapai

Integrasi Smart Attendance Bagi Dosen Sebagai Upaya Peningkatan Kinerja (Irman Effendy)|320 
Smart Attendance bagi dosen agar meningkatnya kinerja terutama dalam bidang kesiplinan atau kehadiran. Hasil dari pengumpulan kebutuhan tersebut seperti yang diperlihatkan pada Gambar 2.

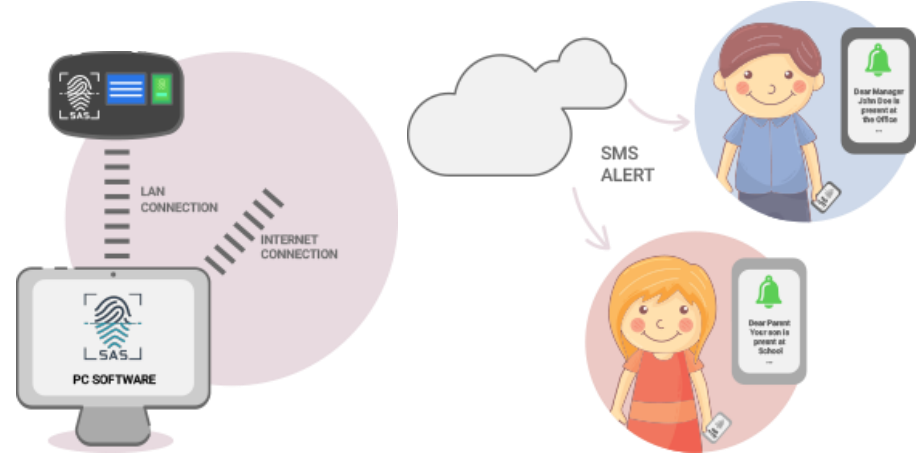

Gambar 2. Arsitektur Smart Attendance

Sesuai Gambar 2 dapat diketahui bahwa proses presensi dilakukan menggunakan sebuah mesin yang memanfaatkan scan sidik jari dan scan wajah. Setelah dosen melakukan presensi maka data otomatis akan tersimpan pada mesin presensi dan juga tersimpan pada server basis data presensi. Untuk melihat rekapitulasi hasil presensi dapat dilihat melalui sistem infomrasi akademik baik untuk pengguna dosen maupun pengguna sumber daya manusia (SDM). Sedangkan untuk melihat notifikasi atau pengecekan oleh dosen untuk memastikan apakah dosen yang bersangkutan telah melakukan presensi atau belum maka dapat dilakukan menggunakan sort message service (SMS) dengan format terntu. Untuk menjalankan atau memberikan notifikasi kepada dosen ketika dilakukan request (permintaan) notifikasi presensi maka arsitektur yang dibuat seperti yang diperlihatkan pada Gambar 3.

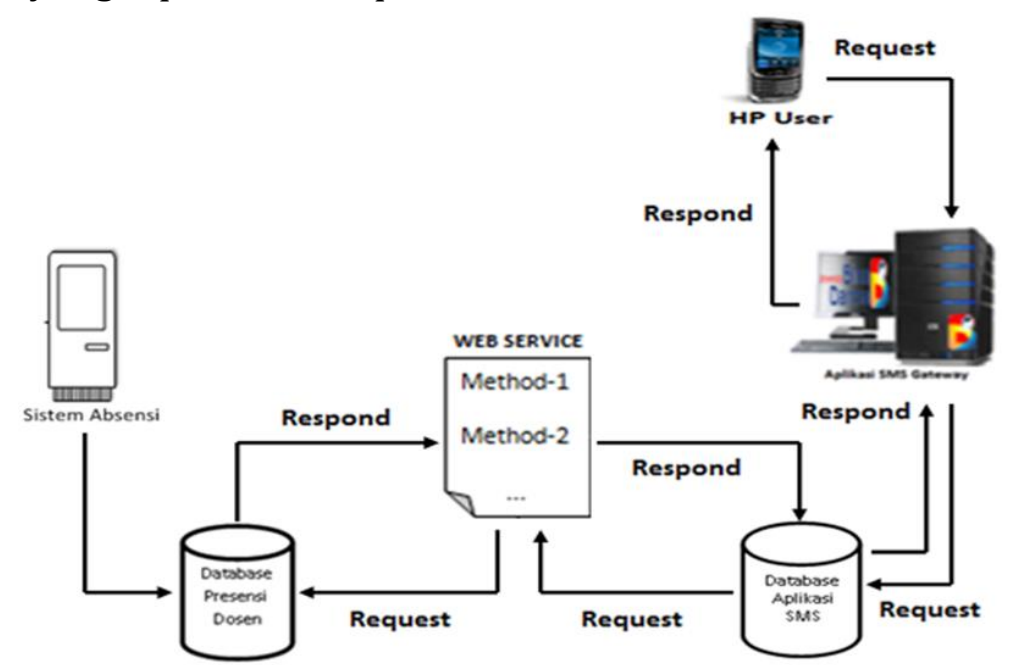

\subsection{Planning}

Gambar 3. Arsitektur Notifikasi Presensi

Planning atau perencanaan terdiri dari tiga tahapan yaitu estimasi, penjadwalan, dan pelacakan. Pada tahapan estimasi dilakukan perhitungan biaya 
yang diperlukan dalam proses pengembangan dan implementasi Smart Attendance. Biaya yang dihitung yaiti biaya pembelian mesin, biaya pembelian server presensi, dan biaya reply sort message service jika dilakukan request oleh dosen. sedangkan fase penjadwalan dilakukan pembuatan jadwal kegiatan pengembangan sampai dengan implementasi. Penjadwalan dibuat sesui dengan proses pengembagan menggunakan waterfall.

\subsection{Modeling}

Sesuai dengan hasil pengeumpulan kebutuhan seperti yang diperihatkan pada Gambar 3. Dimana Smart Attendance menekankan kebutuhan notifikasi bagi dosen untuk mengatasi permasalahan yang dihadapi yaitu (1) dosen sering kali lupa apakah mereka telah melakukan presensi waktu masuk dan pulang, (2) banyaknya permohonan perbaikan presensi oleh dosen yang disebabkan lupa, (3) perekapan presensi bulanan yang terganggu. Untuk itu agar proses pengembangan dapat dilakukan sesuai kebutuhan maka pemodelan dilakukan mengunakan diagram unified modeling language (UML) yang terdiri dari use case diagram dan activity diagram. UML merupakan diagram yang memiliki kemampuan untuk menggambarkan blueprint dari sebuah sistem yang akan dihasilkan [8]. Gambar 4 dapat dilihat use case diagram untuk pemodelan informasi notifikasi pada Smart Attendance.

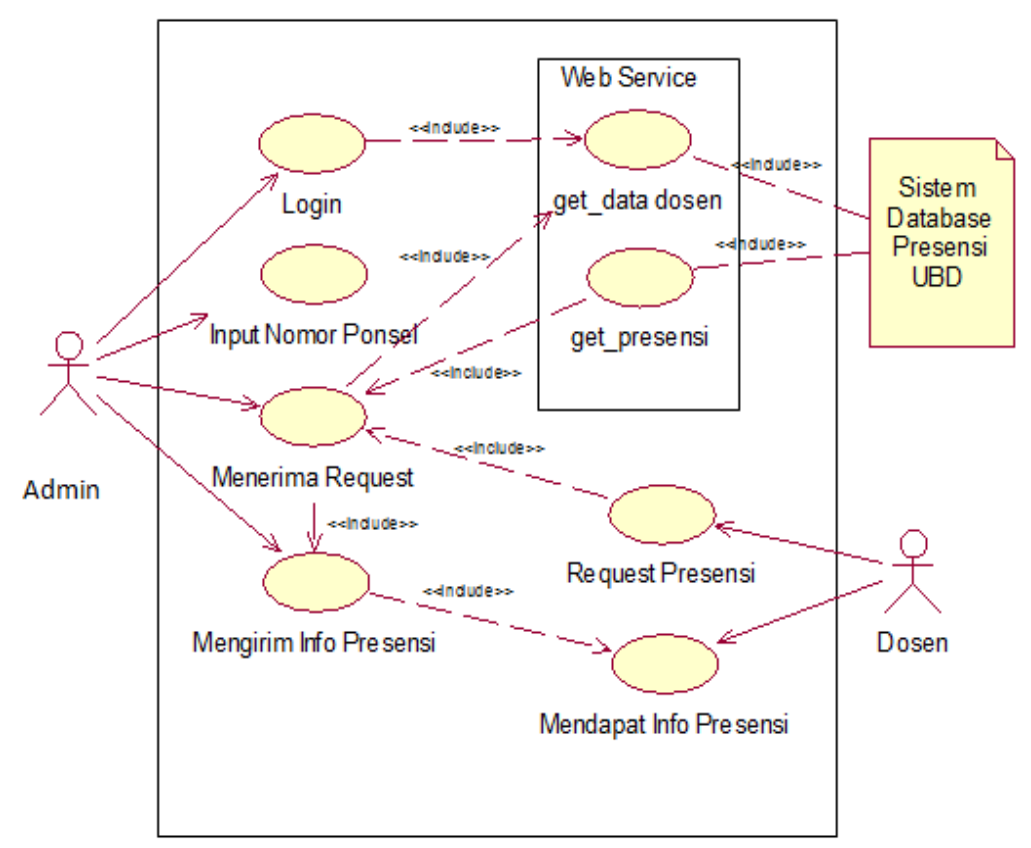

Gambar 4. Use Case Diagram Notifikasi Presensi

Dari Gambar 4 dapat dijelaskan bahwa terdapat dua jenis penguna yang berinteraksi yaitu admin dan dosen. Admin bertugas sebagai pengelolah data sendangka dosen yang melakukan request data. Proses request data yang dilakukan menggunakan web services seperti yang diperlihatkan pada Gambar 6 . Aktivitas atau alur bagaimana dosen melakukan request notifikasi seperti yang diperlihatkan pada Gambar 5. Proses tersebut dimulai dari pengeriman sort 
message service, kemudian sistem mencocokan format yang dikirim, jika cocok maka akan dilanjutkan untuk mengambil data dan lalui dikirim. Sedangkan jika tidak cocok maka akan mengirimkan pesan bahwa format salah.

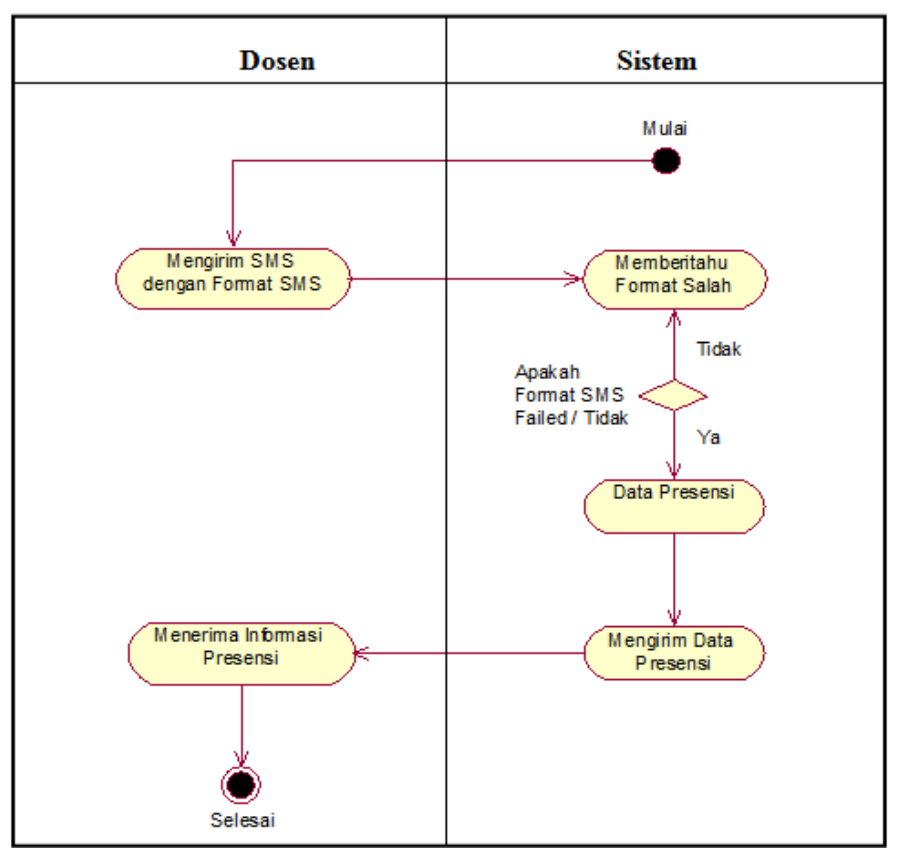

Gambar 5. Use Case Diagram Notifikasi Presensi

\subsection{Construction}

Construction merupakan proses implementasi dari perancangan atau pemodelan yang telah dilakukan. Proses implementasi dilakukan dengan memperhatikan arsitektur notifikasi maupun pemodelan yang telah dihasilkan. Sesuai dengan arsitektur notifikasi seperti yang diperlihatkan pada Gambar 3 dapat diketahui bahwa terdapat dua basis data untuk melakukan notifikasi yaitu basis data presensi dan basis data notifikasi SMS gateway. Dimana untuk mendapatkan data tersebut pengguna harus mengirim pesan singkat atau SMS dengan format yang telah ditentukan maka otomastis akan di-request oleh SMS gateway ke basis data presnsi menggunakan web services. Struktur web service untuk menjembatani penyediaan dan pengambilan data seperti yang di perlihatkan pada Gambar 3. Dari Gambar 3 dapat diketahui data yang ada pada web service berupa data presensi untuk rekapitulasi dalam satu bulan berdasarkan kode dosen masing-masing. Di dalam smart attendance ini juga dibuat notifikasi untuk masing-masing dosen untuk request berdasarkan hari-hari tertentu atau tanggal tertentu. Tujuan dari penyediaan fitur agar dosen dapat melakukan pengecekan apakah yang bersangkutan telah melakukan presensi atau belum. Jika belum maka dosen dapat melakukan presensi sehingga mengurangi kesalahan ketika melakukan perhitungan kinerja. 


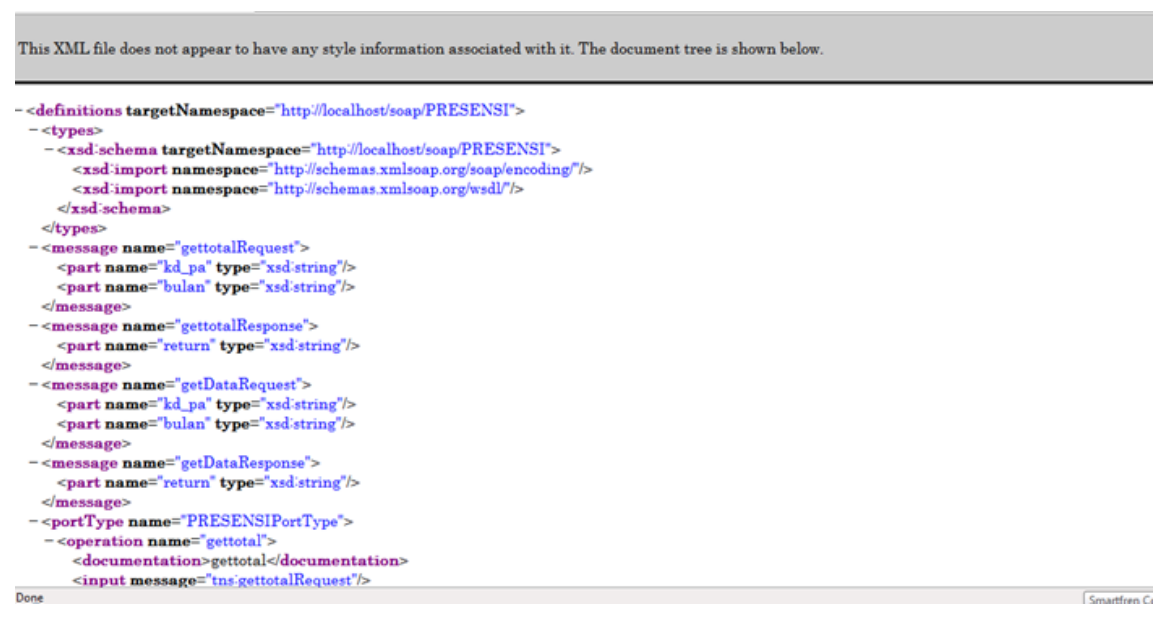

Gambar 6. Struktur Web Service Notifikasi Presensi

Selain struktur web service seperti yang diperlihatkan pada Gambar 6 merupakan struktur untuk menjembatani komunikasi data. Komunikasi yang dimaksud yaitu komunikasi antara basis data presensi dengan basis data notifikasi yang digunakan untuk memberikan informasi notifikasi presensi. Selain dengan menggunakan fasilitas notifikasi terdapat juga rekapitulasi yang disediakan pada sistem informasi akademik seperti yang diperlihatkan pada Gambar 7.
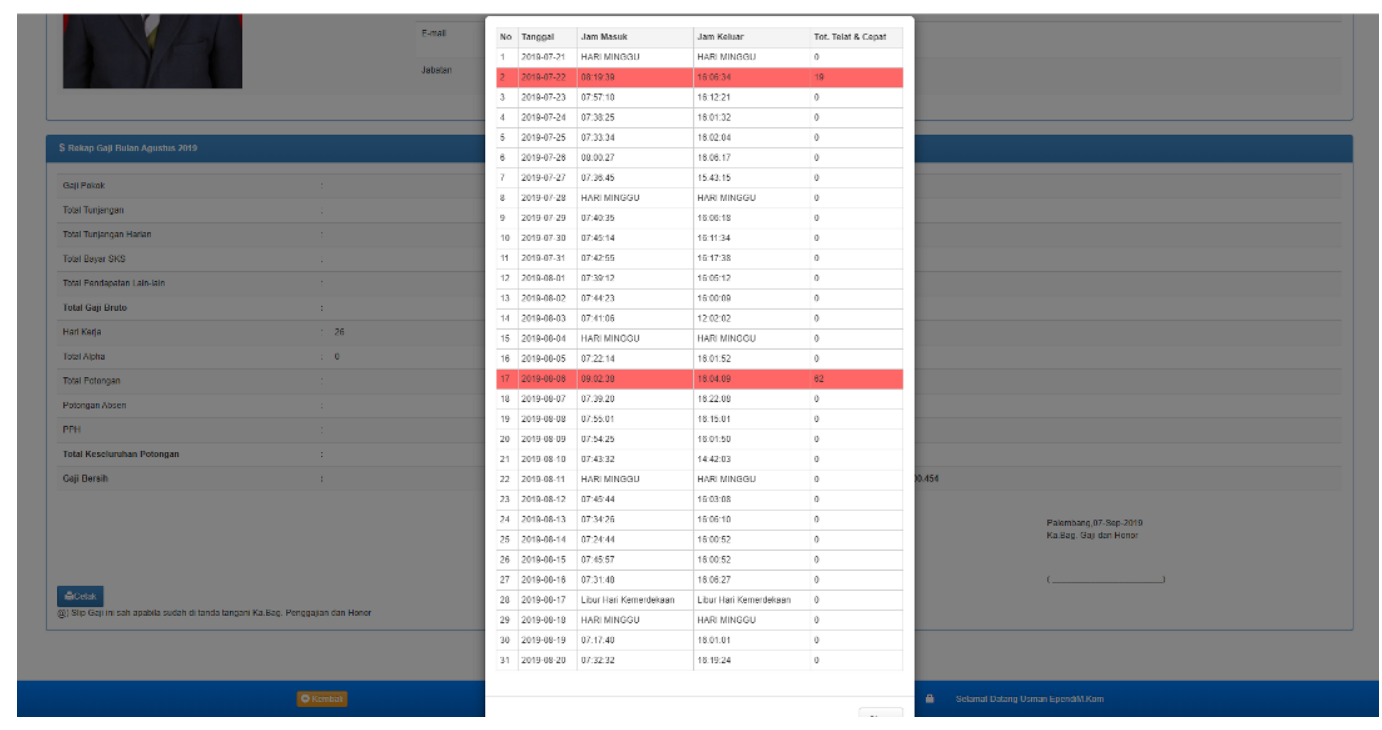

Gambar 7. Rekapitulasi Presensi Bulanan

Rekapitulasi presensi yang ditampilkan seperti pada Gambar 7 merupakan data presensi yang dilakukan oleh dosen. Presensi dengan latar merah menunjukkan presensi yang dilakukan dosen tidak sesuai dengan ketentuan yang telah dibuat seperti terlambat jam datang atau kecepatan jam pulang. Untuk melakukan presensi dapat dilakukan denang dua acara yaitu scan sidik jari dan wajah pada mesin presensi seperti yang diperlihatkan pada Gambar 8. Data presensi yang diambil sebagai pelaporan baik untuk notifikasi maupun pelaporan 
kinerja ditentukan sebagai berikut yaitu: (1) presensi datang, diambil untuk data pertama kali presensi dengen membandingkan waktu presensi bersumber dari mesin-mesin presensi yang tersedia, (2) presensi pulang, diambil untuk data terakhir kali presensi dengen membandingkan waktu presensi bersumber dari mesin-mesin presensi yang tersedia.

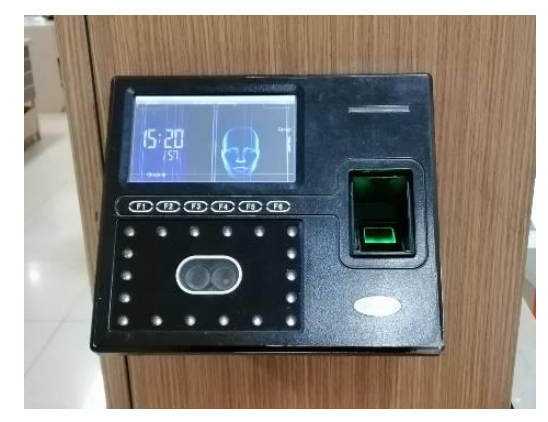

Gambar 8. Mesin Presensi

Untuk menjalankan smart attendance terutama notifikasi maka disediakan sebuah server khusus yang bertugas menjawab secara otomatis request (permintaan) notifikasi presensi. Pada server tersebut disediakan aplikasi notifikasi menggunakan SMS dengan fungsi memberikan reply terhadap SMS yang masuk dari dosen seprti yang diperlihatkan pada Gambar 9. Notifikasi yang diberikan oleh server presensi jik format SMS dinyatakan benar yaitu presensi( JIDDosen( )Taggal( )Bulan( )Tahun. Untuk melakukan request (permintaan) notifikasi tidak ditentukan nomor handphone tertentu atau dari nomor handphone mana saja dapat dilakukan. Kondisi tersebut dengan pertimbangan atau asumsi seorang dosen dapat saja merubah nomor handphone yanf ia miliki.

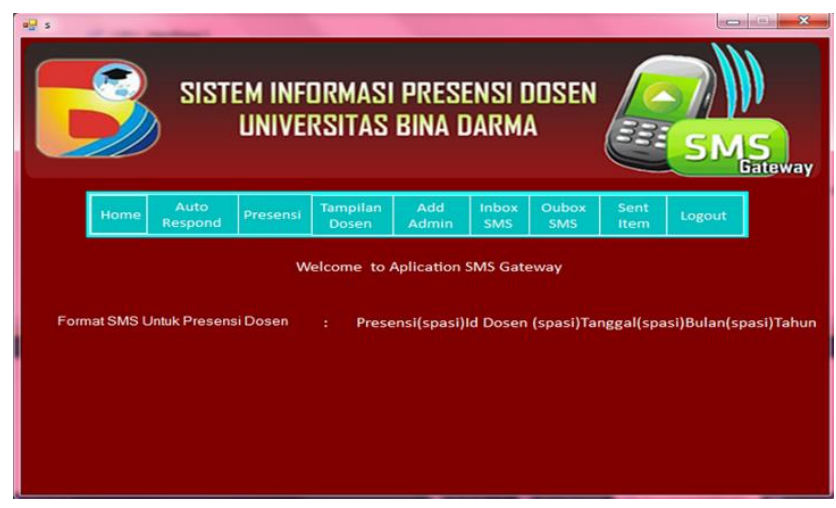

\section{SIMPULAN}

Gambar 9. Aplikasi Notifikasi Status Presensi

Sesuai dengan uraian yang telah dikemukakan maka dapat disimpulkan beberapa poin sebagai berikut:

a. smart attendance yang dihasilkan dapat diintegrasikan dan dapat memberikan layanan presensi yang akurat. 
b. smart attendance yang dihasilkan dapat dijadikan bahan atau sumber data utama dalam memberikan penilaian kinerja karena data yang ada pada smart attendance memiliki nilai integritas karena dapat selalu dipantau oleh masingmasing dosen.

c. Dosen dapat secara detail melihat hasil presensi yang telah dilakukan baik semalui sistem akademik maupun notifikasi sehingga dapat mengukur sendiri nilai kinerja terutama bidang disiplin.

\section{DAFTAR PUSTAKA}

[1] A. H. Triatmoko, S. H. Pramono, and H. S. Dachlan, "Penggunaan Metode ViolaJones dan Algoritma Eigen Eyes dalam Sistem Kehadiran Pegawai," Jurnal Eeccis, vol. 8, no. 1, pp. 41-46, 2014.

[2] R. Andriyani, "Proses Penilaian Kinerja Dosen Universitas Bina Darma," Suyanto, Ed., ed. Palembang: Universitas Bina Darma, 2019.

[3] N. K. Wardhani and M. T. A. Aziz, "SISTEM INFORMASI MANAJEMEN SUMBER DAYA MANUSIA BERBASIS WEB (STUDI KASUS: PT. KLIK TEKNOLOGI INDONESIA)," Jurnal Techno Nusa Mandiri, vol. 15, no. 2, pp. 145-152, 2018.

[4] Q. Aini, U. Rahardja, and F. Allamiah, "Perancangan Sistem Absensi Kinerja Pengabdian Tri Dharma secara Online pada Website Berbasis YII Framework," Sisfotenika, vol. 8, no. 1, pp. 13-22, 2018.

[5] U. Ependi, "Heuristic Evaluation for Mobile Application (Studi Kasus: Aplikasi Depo Auto 2000 Tanjung Api Api Palembang)," Simetris: Jurnal Teknik Mesin, Elektro dan Ilmu Komputer, vol. 8, no. 2, pp. 563-570, 2017.

[6] U. Ependi and N. Oktaviani, "Abstract Keyword Searching with Knuth Morris Pratt Algorithm," Scientific Journal of Informatics, vol. 4, no. 2, pp. 150-157, 2017.

[7] R. S. Pressman, "Rekayasa Perangkat Lunak Pendekatan Praktisi (Edisi 7)," Yogyakarta: Andi, 2011.

[8] U. Ependi, "Pemodelan Sistem Informasi Monitoring Inventory Sekretariat Daerah Kabupaten Musi Banyuasin," KLIK-KUMPULAN JURNAL ILMU KOMPUTER, vol. 5, no. 1, pp. 49-60, 2018. 